10

\title{
Тонкопленочные нелинейно-оптические кристаллы для внутрирезонаторной электрооптической модуляции
}

\author{
() О.Д. Вольпян ${ }^{1}$, И.Ю. Денисюк ${ }^{2,}$, Ю.А. Обод ${ }^{3}$, М.И. Фокина ${ }^{2}$, Ю.А. Игнатьева ${ }^{2}$, Е.Б. Шекланова ${ }^{2}$ \\ ${ }^{1} \mathrm{OОO} \mathrm{„НПК} \mathrm{Фотрон-Авто“,}$ \\ 115191 Москва, Россия \\ 2 Университет ИТМО, \\ 197101 Санкт-Петербург, Россия \\ ${ }^{3}$ Научно-технологический центр уникального приборостроения РАН, \\ 117342 Москва, Россия \\ ๆ e-mail: denisiuk@mail.ifmo.ru
}

Поступила в Редакцию 08.06.2020 г.

В окончательной редакции 08.07.2020 г.

Принята к публикации 28.08.2020 г.

Проведено исследование методов получения монокристаллических пленок DAST (4- $N, N$-dimethylamino$4^{\prime}-N^{\prime}$-methyl stilbazolium tosylate) толщиной в единицы микрометров, предназначенных для электрооптической модуляции. Получены тонкопленочные монокристаллы, форма и спектр поглощения которых подтверждает их кристаллическую структуру „красной“ кристаллической формы DAST. Однородное свечение в режиме поляризационного контраста показывает их монокристалличность и однородную ориентацию. Материалы предназначены для внутрирезонаторной модуляции лазерного излучения.

Ключевые слова: молекулярный кристалл, DAST, электрооптика, рост кристаллов, монокристаллическая пленка.

DOI: $10.21883 /$ OS.2020.11.50178.132-20

\section{Введение}

Использование внутрирезонаторных электрооптических модуляторов - эффективный способ управления и контроля параметров генерируемого излучения $[1,2]$. В качестве активных материалов для таких модуляторов чаще всего используют классические электрооптические материалы [3] и тонкие графеновые пленки [1,4]. Основное требование к таким материалам - высокое значение электрооптического коэффициента и минимум вносимых потерь. В последнее десятилетие получил значительное развитие новый класс электрооптических материалов органические электрооптические кристаллы со сверхвысокими значениями электрооптических параметров [5]. Среди них наивысшие параметры имеют кристаллы 4-N, N-dimethylamino- $4^{\prime}-N^{\prime}$-methyl stilbazolium tosylate (DAST), которые могут быть использованы для внутрирезонаторной модуляции. Кристаллы DAST характеризуются стабильностью при температуре до $250^{\circ} \mathrm{C}$, низкой величиной диэлектрической проницаемости $\varepsilon=5.2$, электрооптическим коэффициентом $98 \mathrm{pm} / \mathrm{V}$, а для тонких пленок - до $700 \mathrm{pm} / \mathrm{V}$ [6].

Основной метод выращивания кристаллов DAST основан на получении насыщенного раствора DAST в безводном метаноле при температуре $50^{\circ} \mathrm{C}$ с последующим медленным, порядка $0.5^{\circ}$ в день, понижением температуры. При этом в определенный момент пересыщение раствора достигает точки спонтанной кристаллизации и начинается рост кристаллов. Поскольку молекулы в кристалле расположены планарно, скорость роста плос- кости превышает скорость роста в толщину примерно в 20 раз. Для дальнейшего повышения скорости 2D роста необходимо создать условия роста, различные по осям, например с использованием активных подложек.

В работе [7] рассмотрен метод роста тонкопленочного монокристалла DAST толщиной $4 \mu \mathrm{m}$ и формирование на нем электрооптического поляризационного модулятора, работающего на частоте $1.5 \mathrm{GHz}$. Для получения монокристаллической пленки в работе использован модифицированный метод сдвига. В этом случае подложка представляет собой две стеклянные пластины, расположенные с малым зазором и медленно движущиеся друг относительно друга во время роста кристалла. Недостаток метода - малый зазор между пластинами и появление царапин на поверхности растущей пленки при движении пластин.

Другой способ, позволяющий увеличить скорость роста монокристаллической пленки в плоскости и уменьшить скорость роста в толщину, основан на взаимодействии растущего кристалла с подложкой и называется жидкостной эпитаксией, он был использован, например, в работе [8]. Подобный эпитаксиальный метод можно использовать и при росте кристалла DAST; например, в ходе работы по гранту РФФИ 05-02-08048 (рук. Денисюк И.Ю.) исследован метод получения планарных тонкопленочных кристаллов DAST, сформированных на активной поверхности подложки 2-Carboxyethylacrylate, с использованием взаи- 
модействия кислотных групп мономера с молекулами DAST [9].

В работе [9] кристаллы выращены из пересыщенного раствора DAST при равномерном снижении температуры, чем обеспечивается необходимая величина пересыщения. Размеры полученных кристаллов $4 \times 5 \times 0.005 \mathrm{~mm}$. Толщина $5 \mu \mathrm{m}$ была обусловлена взаимодействием растущего кристалла с кислотными группами подложки, что приводило к ускорению роста в ее плоскости.

\section{Условия эксперимента}

В данной публикации исследовался метод получения тонкопленочных нелинейно-оптических кристаллов DAST, ориентированный на получение пленок толщиной менее $1 \mu \mathrm{m}$. Рост кристаллов производился из раствора в метаноле при медленном снижении температуры со скоростью $0.5-1{ }^{\circ} \mathrm{C}$ в день, начальное пересыщение обеспечивалось быстрым снижением температуры насыщенного раствора DAST с 50 до $45^{\circ} \mathrm{C}$. Также в ряде случаев использовано медленное испарение растворителя по полоскам фильтровальной бумаги, положенной под крышку эксикатора.

Исследование кристаллов выполнялось с использованием универсального микроскопа Olympus STM6 с цифровым измерением размеров. Оценивались форма кристалла и соотношение линейных размеров и толщины. Для измерения спектров использован спектрофотометр Shimadzu UV-1800.

\section{Результаты и их обсуждение}

Исходя из необходимости получения тонкопленочного монокристалла для использования во внутрирезонаторной модуляции, были исследованы два метода.

1. Метод капиллярного роста, основанный на росте кристалла DAST в зазоре между двумя стеклянными поверхностями, затекание раствора в который обусловлено капиллярными силами. Метод в общем плане описан в обзоре [10].

Система для роста планарных кристаллов (рис. 1) состоит из двух стекол, поверхность которых предварительно активировалась смесью $37 \%$ перекиси водорода и концентрированной серной кислоты. В результате активации поверхность стекла оказывается покрыта ОНгруппами. Зазор между стеклами задается заложенными между ними прокладками толщиной 100 или $10 \mu \mathrm{m}$. В объеме 2 (рис. 1) находится $3 \mathrm{ml}$ насыщенного раствоpa DAST в метаноле, который втягивается в зазор между стеклами за счет капиллярных сил. Вся система устанавливалась в эксикатор, медленное испарение метанола обеспечивалось двумя полосками фильтровальной бумаги под крышкой. Предварительно был приготовлен насыщенный раствор DAST в метаноле, насыщение которого проводилось при $50^{\circ} \mathrm{C}$. Раствор отделялся от

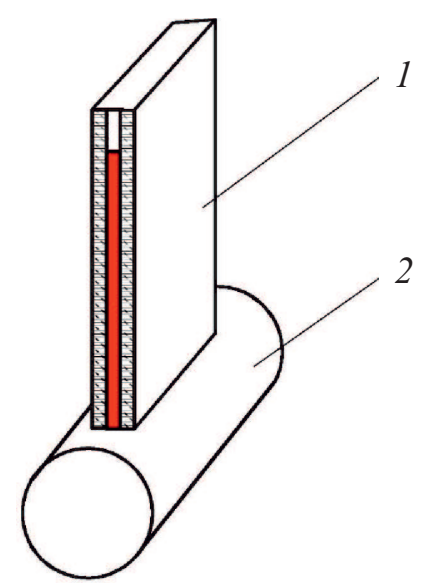

Рис. 1. Схема капиллярного выращивания планарных кристаллов: два стекла с заданным зазором, в котором происходит рост кристалла (1), емкость для ростового раствора (2).
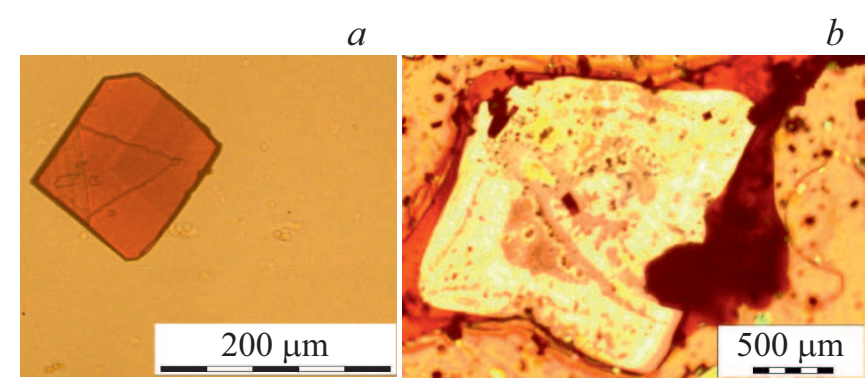

Рис. 2. Кристаллы DAST: $(a)$ полученный в зазоре между стеклами, толщина $1 \mu \mathrm{m}$, форма соответствует классической для DAST (наличие скосов на двух углах); (b) монокристаллическая пленка DAST, выращенная по эпитаксиальному методу на поверхности полиакриловой кислоты. Поляризационный контраст, отраженный свет.

осадка декантацией. После заливки раствора в систему и снижения температуры с 50 до $45^{\circ} \mathrm{C}$ производилось медленное снижение температуры до $37^{\circ} \mathrm{C}$ со скоростью $2^{\circ}$ в день при медленном испарении метанола. Таким образом пересыщение раствора обеспечивалось одновременно и снижением температуры, и испарением растворителя.

При этом в системе с зазором между стеклами $100 \mu \mathrm{m}$ образовались обычные, достаточно толстые кристаллы, ориентирующее влияние стекла и зазора не наблюдалось. В системе с зазором $10 \mu \mathrm{m}$ образовались хорошо ориентированные планарные кристаллы. Размеры кристаллов составляют от 150 до $500 \mu \mathrm{m}$, толщина менее $1 \mu \mathrm{m}$ (рис. 2, $a$ ).

2. Второй исследованный метод был вариацией эпитаксиального роста, описанного в работе [10]. На подложку был нанесен слой мономерной композиции из 90\% акриловой кислоты (АО Вектон), 10\% гександиолдиакрилата 1,6-hexandioldiacrylate, Aldrich № 24681-6) и фотоинициатора. После нанесения слоя толщиной $1 \mu \mathrm{m}$ он был фотополимеризован с получением твердой пленки полиакриловой кислоты, имеющей 


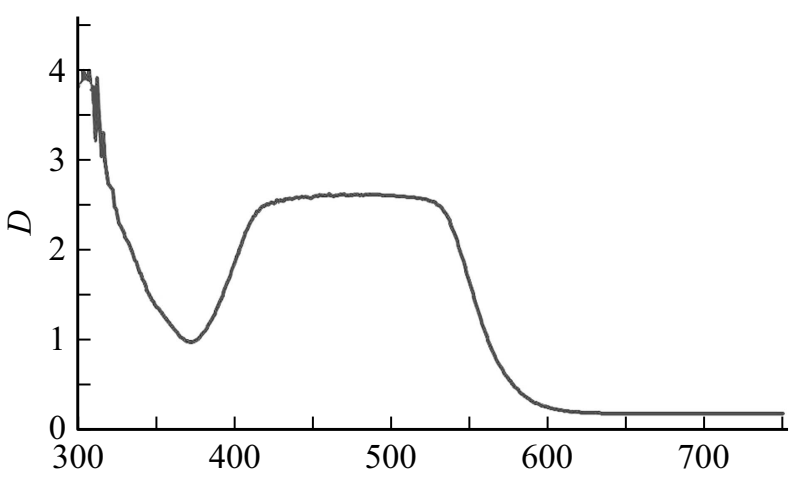

Рис. 3. Спектр поглощения монокристаллической пленки, выращенной на активной подложке.

большую концентрацию кислотных групп на поверхности. Подложка с покрытием из полиакриловой кислоты была установлена в наклонном положении в бюкс с насыщенным раствором DAST в метаноле при температуpe $50^{\circ} \mathrm{C}$, а бюкс поставлен в эксикатор. Температурный режим роста тот же, что и в предшествующем случае.

По окончании процесса и извлечении подложки на ней были обнаружены планарные тонкие монокристаллические пленки DAST толщиной около $1 \mu \mathrm{m}$ и размером несколько миллиметров (рис. 2,b). Фотография, представленная на рис. $2, b$, сделана в отраженном свете в режиме поляризационного контраста. Однородная яркость кристалла показывает, что поляризация его однородна и это монокристалл. При существенном уменьшении толщины подслоя полиакриловой кислоты можно ожидать формирование кристаллов более правильной формы, фиксированных на подложке.

На рис. 3 приведен спектр поглощения полученной монокристаллической пленки. Сравнение полученного спектра с известными спектрами поглощения монокристаллов DAST разных кристаллических форм [11] демонстрирует формирование некоторой кристаллической модификации DAST, близкой к „красной“ кристаллической форме. Согласно работе [11], для „красной“ кристаллической формы DAST характерно наличие максимума поглощения $530-550 \mathrm{~nm}$, который плавно снижается до $450 \mathrm{~nm}$, и наличие минимума поглощения в области $350-400 \mathrm{~nm}$. Напротив, DAST в молекулярном и аморфном состояниях характеризуется одним максимумом на длине волны $450 \mathrm{~nm}$. Некоторое отличие формы спектра полученной пленки от спектра монокристалла может быть объяснено ориентирующим действием подложки и малой толщиной монокристаллической пленки.

Предполагаемое применение тонкопленочных кристаллов - планарные низковольтные модуляторы света. Большая величина электрооптического коэффициента порядка $400 \mathrm{~nm} / \mathrm{V}$ и низкое значение диэлектрической проницаемости - 5.2 [12] позволяют получить низковольтный (до $5 \mathrm{~V}$ ) и высокочастотный (до $1 \mathrm{GHz}$ ) модулятор света. Размер кристалла может быть увеличен до $5 \times 5 \mathrm{~mm}$ при уменьшении скорости роста, что будет выполнено в дальнейшей работе.

\section{Выводы}

Исследованные методы получения монокристаллических пленок DAST показали возможность их роста как минимум двумя методами. При уменьшении скорости роста можно рассчитывать на получение больших по размеру поликристаллических пленок. Форма полученных планарных кристаллических пленок (ромбическая) и спектр поглощения показывают образование „красной“ кристаллической формы DAST, обладающей наибольшей величиной электрооптической восприимчивости. Монокристаллические пленки могут быть использованы для электрооптической модуляции света.

\section{Финансирование работы}

Работа выполнена при поддержке Министерства науки и высшего образования Российской Федерации в рамках Федеральной целевой программы „Исследования и разработки по приоритетным направлениям развития научно-технологического комплекса России на 2014-2020 годы“. Соглашение № 07515-2019-1299. Уникальный идентификатор соглашения RFMEFI60718X0206.

\section{Список литературы}

[1] Lee C.-C., Mohr C., Bethge J., Suzuki S., Fermann M.E., Hartl I., Schibli T.R. / Optics Lett. 2012. V. 37. N 15. doi 10.1364/OL.37.003084

[2] Yoshiaki Nakajima, Hajime Inaba, Kazumoto Hosaka, Kaoru Minoshima, Atsushi Onae, Masami Yasuda, Takuya Kohno, Sakae Kawato, Takao Kobayashi, Toshio Katsuyama, Feng-Lei Hong // Optics Express. 2010. V. 18. Iss. 2. P. 1667-1676. doi 10.1364/OE.18.001667

[3] Hudson D.D., Holman K.W., Jones R.J., Cundiff S.T., Ye J., Jones D.J. // Optics Lett. 2005. V. 30. Iss. 21. P. 2948-2950. doi 10.1364/OL.30.002948

[4] Bulatova A., Bulatov M., Starov D. // Russian Phys. J. 2012. V. 54. N 12. P. 1401. doi 10.1007/s11182-012-9761-1

[5] Figi H., Jazbinšcek M., Hunziker C., Koechlin M., Günter P. // Opt. Express. 2008. V. 16. N 15. P. 11310. doi 10.1364/OE.16.011310

[6] Pan F., Knopfle G., Bosshard Ch., Follonier S., Spreiter R., Wong M.S., Gunter P. // Appl. Phys. Lett. 1996. V. 69. N 1. P. 13.

[7] Thakur M., Mishra A., Titus, J., Ahyi A. C. // Appl. Phys. Lett. 2002. V. 81. N 20. P. 3738. doi $10.1063 / 1.1520713$

[8] Bulatov M.F., Churikov D.V. // J. Surface Investigation: Xray, Synchrotron and Neutron Techniques. 2019. V. 13. N 2. P. 206-209. doi 10.1134/S1027451019020046

[9] Денисюк И.Ю., Бурункова Ю.Э., Смирнова Т.В. // Оптический журн. 2007. Т. 74. № 2. С. 63.

[10] Manetta S., Ehrensperger M., Bosshard C., Günter P. // Comptes Rendus Physique. 2002. V. 3. N 4. P. 449. doi 10.1016/S1631-0705(02)01338-5

[11] Bhowmik A.K., Xu J., Thakur M. // Appl. Phys. Lett. 1999. V. 75. N 21. P. 3291.

[12] Jazbinsek M., Mutter L., Günter P. // IEEE J. of Selected Topics in Quantum Electronics. 2008 V. 14. N 5. doi 10.1109/JSTQE.2008.921407 